\title{
A low-cost, high-efficiency, new generation material for fog harvesting fumed silica-doped polypropylene
}

\author{
i. Afșin Kariper $\mathbb{D}^{1,2 \otimes}$
}

This study describes the development of a fog collector material for fog harvesting. Polypropylene (PP) doped with fumed silica $(0-2 \%)$ was punctured at equal intervals and exposed to fog produced by a humidifier. The amount of water harvested by each sample was measured using an ultrasonic fogger. Polypropylene doped with $1 \%$ fumed silica was most effective at harvesting water, and collected almost 19-20 times more water than pure polypropylene. This improvement is due to the surface tension, which decreased from $16.754 \mathrm{mN} / \mathrm{m}$ (pure PP) to 13.512 and $9.992 \mathrm{mN} / \mathrm{m}(0.5 \%$ and $1 \%$ fumed silica, respectively). On the other hand, when fumed silica doping exceeded 1\%, this increased the polymer's surface tension, measured as 20.6 and $38.1 \mathrm{mN} / \mathrm{m}$ for 1.5 and $2 \%$ fumed silica doping. We therefore propose fog harvesting using $1 \%$ fumed silica-doped polypropylene as a low-cost method for collecting clean water in arid regions.

npj Clean Water (2021)4:24; https://doi.org/10.1038/s41545-021-00117-2

\section{INTRODUCTION}

The boiling degree of water is $100^{\circ} \mathrm{C}$, and its freezing degree is $0{ }^{\circ} \mathrm{C}$. Water is molecularly V-shaped. The distance between the two protons is $\sim 104.45^{\circ}$. Without this angle and geometric shape, one could not talk about life. Thanks to these features, the dipole moment is $1.84 \mathrm{D}$, and the surface tension is $72.8 \mathrm{mN} / \mathrm{m}$. Due to the high surface tension, water takes the shape of a sphere to reduce the surface energy.

Water is one of the natural resources that human beings will suffer the most from its absence in the future. Even now, water scarcity has begun in many parts of the world, and people are particularly in need of clean water. Polluted clean water resources are tried to be purified, but this increases the cost of obtaining clean water. Recently, researchers have developed engrossing and low-cost methods to meet the need for clean water. The collection of rainwater in definite reservoirs is a good example. However, the collection of rainwater only in a limited area and the fact that there is no rainfall in arid regions caused the studies in this field to cease. On the other hand, fog harvesting is quite an interesting subject. It is possible to collect water formed by sweating on the material in foggy areas and hot arid regions.

Researchers have produced many different materials for fog harvesting ${ }^{1-3}$. Because the structure and type of fog collector materials used for fog harvesting also differ according to the region to be used. Therefore, researchers have produced new materials by examining the creatures living in different regions and collecting water even though there is no water source ${ }^{4-7}$. Cicada, cactus, and spider webs are natural fog collectors ${ }^{1-3}$. Researchers have noticed that these creatures collect water through hydrophobic materials.

The lowest-cost fog collector materials known as artificial materials are the ones produced from polymers such as polypropylene (PP). However, PP cannot collect as much water as other materials. Another example is the variation of polyethylene terephthalate fibers' ability to collect water depending on their surface and cross-sectional area ${ }^{4}$. The materials prepared with silicone elastomers and fluoropolymers, which have superhydrophobic surfaces, have higher efficiency depending on their surface properties ${ }^{5,6}$. For example, polyacrylonitrile (PAN) is considered suitable because of its mechanical properties ${ }^{7}$. Many studies have been examined polymers for water vapor transport. Akhtar and Peineman used block copolymer membranes $^{8}$ and Pebax ${ }^{\oplus} 1657 /$ Graphene oxide composite membranes $^{9}$ for water separation. Recently, very important improvements have been reported in this area with rugged structures covered with polymer on a hydrophobic surface and doping with $\mathrm{TiO}_{2}$ nanoparticles ${ }^{10-12}$. It was discovered that convex surface, lump-like tissues increase the fog condensation rate to the maximum level ${ }^{13-15}$. For an efficient fog harvest, micro and nano coatings alone remained insufficient, and it is understood that additional coatings are needed.

According to the researchers, hydrophilic surfaces coated with a superhydrophobic substrate are needed to prevent the fog hitting the material's surface from adhering to the surface. The interaction between the hydrophilic parts and the superhydrophobic surface must be strong to increase the liquid's contact angle with the solid surface. To increase this interaction, researchers have started to focus on knitted structures. These braided structures are materials with different lattice structures consisting of polymers and metals ${ }^{16-20}$. Polymers are preferred in researches because of their flexibility, high strength, and mechanical endurance. One of the best examples of them is polystyrene (PS). PS can be used as a substrate since it has glass transition temperatures around $80-100^{\circ} \mathrm{C}$ and low processing temperature ${ }^{21}$.

Researchers suggested that the water to be collected affects the hydrophobic and hydrophilic regions' boundary and fog harvest productivity $^{22}$. Some researchers have shown that the super hydrophilic surface's harvesting performance on the superhydrophobic surface changes depends solely on the inclination angle ${ }^{23}$. According to these results, the modified surface's fog harvesting performance is strongly influenced by wettability changes, such as the compressive strength and the harvest conditions. These results are presented in a review by Korkmaz and Kariper ${ }^{24}$.

When the studies are summarized, it is concluded that both hydrophilic and hydrophobic surface interactions are important in fog collecting materials, and these materials should be used together.

\footnotetext{
${ }^{1}$ Education Faculty, Erciyes University, Kayseri, Turkey. ${ }^{2}$ Erciyes Teknopark, Kayseri, Turkey. ${ }^{\varpi}$ email: akariper@gmail.com
} 
Many studies have been carried out for fog harvesting using PP, which is very cost-effective. Raut et al. produced $0.2 \mu \mathrm{m}$ porous fiber textile products with PP and polycarbonate. They proved that a nonperforated flat strip of pure PP could store $0.18 \mathrm{~g} / \mathrm{cm}^{2} / \mathrm{h}$ of water. They found the water contact angle of the pure PP strip $97^{\circ 25}$. Moazzam et al. proved that $0.097 / \mathrm{cm}^{2} / \mathrm{h}$ water could be stored with their polydopamine coated PP. The contact angle of the material with water was found to be $\sim 14^{\circ}$, and they calculated the surface tension as $87.9 \mathrm{mN} / \mathrm{m}^{26}$. Chin et al. produced a PP membrane using the electrospun method to purify water from saline water. They announced that they managed to desorb 30\% of the saline water ${ }^{27}$. Up to now, a maximum of $0.18 \mathrm{~g} / \mathrm{cm}^{2} / \mathrm{h}$ water can be stored with $\mathrm{PP}^{25}$. The most interesting example is the article published by Damak and Varanasi in 2018 on electrostatic fog harvesting. Their study formed mathematical formulas that link many parameters such as voltage, wind speed, etc., to be applied for more efficient fog harvesting ${ }^{28}$. Shi et al. used a vertical wire system to show the system's effect on the produced material's fog harvesting efficiency. The study explained that the vertical wire system could store three times more water than the other wire system, and they designed a machine for fog harvesting for the first time ${ }^{29}$.

In practice, the harvesting materials produced are usually stretched between two poles. Under the poles, there are water collection pipes and water collection tanks in which the pipes flow. The produced water is stored in these tanks ${ }^{30,31}$. Batisha showed the best example of using fog harvesting in 2015. Batisha talked about its applications in many countries such as Chile, Yemen, Amman, and Spain and interpreted the economic, environmental, and social dimensions of fog harvesting materials ${ }^{32}$.

Besides, this is not the first use of fumed silica (FS). Previously, Mavukkandy et al. used FS particles as porogen to prepare polyvinylidene fluoride (PVDF) membranes. In the study, they were able to add $5 \%$ of FS to PVDF. They studied the thermodynamic and kinetic aspects of membrane formation. They noticed that the emerging membrane morphology was associated with thermodynamic enhancement and FS doping rate and kinetic inhibition. They used the prepared membranes for the filtration of raw wastewater. They found that although the PVDF-FS mixed membrane showed a much higher current, they also had a high fouling tendency due to their increased hydrophobicity. They found that PVDF-FS membranes used for water filtration are suitable for water purification and pollution problem ${ }^{33}$.

In this study, a substrate was produced by adding a hydrophilic material to a hydrophobic material and tested in a single layer. FS and molecular sieve were doped to the PP in an extruder machine at low percentage rates. The results were interesting.

\section{RESULTS}

\section{Fourier transform infrared (FTIR) analyses}

FTIR analyses $\left(200-600 \mathrm{~cm}^{-1}\right)$ are given in Fig. 1a-e. FTIR analyses were performed in the wavelength range of $200-600 \mathrm{~cm}^{-1}$ to see both PP and Si-O vibrations. The region above $600 \mathrm{~cm}^{-1}$ was not included because the $700 \mathrm{~cm}^{-1}$ regions are already known, and doped PP and Si's vibration peaks will be better seen under $700 \mathrm{~cm}^{-1}$. As expected, out of plane deformation of Si-O at $450-460 \mathrm{~cm}^{-1}$, which is not seen much in pure PP, became more apparent as doped $\mathrm{Si}$ increases ${ }^{34}$. $-\mathrm{CH}_{2}$ and bending $-\mathrm{CH}$ vibrations (at 450 and $240-250 \mathrm{~cm}^{-1}$, respectively), which are very weak in pure, undoped PP, are further enhanced by Si-O vibrations' contribution. Besides, $-\mathrm{CH}$ vibrations at $279 \mathrm{~cm}^{-1}$ disappeared within the $\mathrm{SiO}_{2}$ crystal vibrations ${ }^{35}$. $\mathrm{Si}-\mathrm{O}$ vibrations in the structure become dominant with $2 \%$ FS doping. When the doping exceeds $2 \%$ by weight, deterioration occurs in the polymer structure, and the extrusion machine fails to produce strips from the polymer. FTIR analyses $\left(450-4000 \mathrm{~cm}^{-1}\right)$ are given in Fig. $1 \mathrm{f}-\mathrm{j}$. Aliphatic $-\mathrm{CH}$ vibration peaks are observed at $2800-2900 \mathrm{~cm}^{-1}$. Si-O-Si at $1165 \mathrm{~cm}^{-1}$, Si-O at $1372-1453 \mathrm{~cm}^{-1}$, and $\mathrm{Si}-\mathrm{OH}$ vibration peak at $969 \mathrm{~cm}^{-1}$. Characteristic vibrations of terminal unsaturated- $\mathrm{CH}_{2}$ groups present in isotactic PP are identified at 843-808 and $1001 \mathrm{~cm}^{-136,37}$.
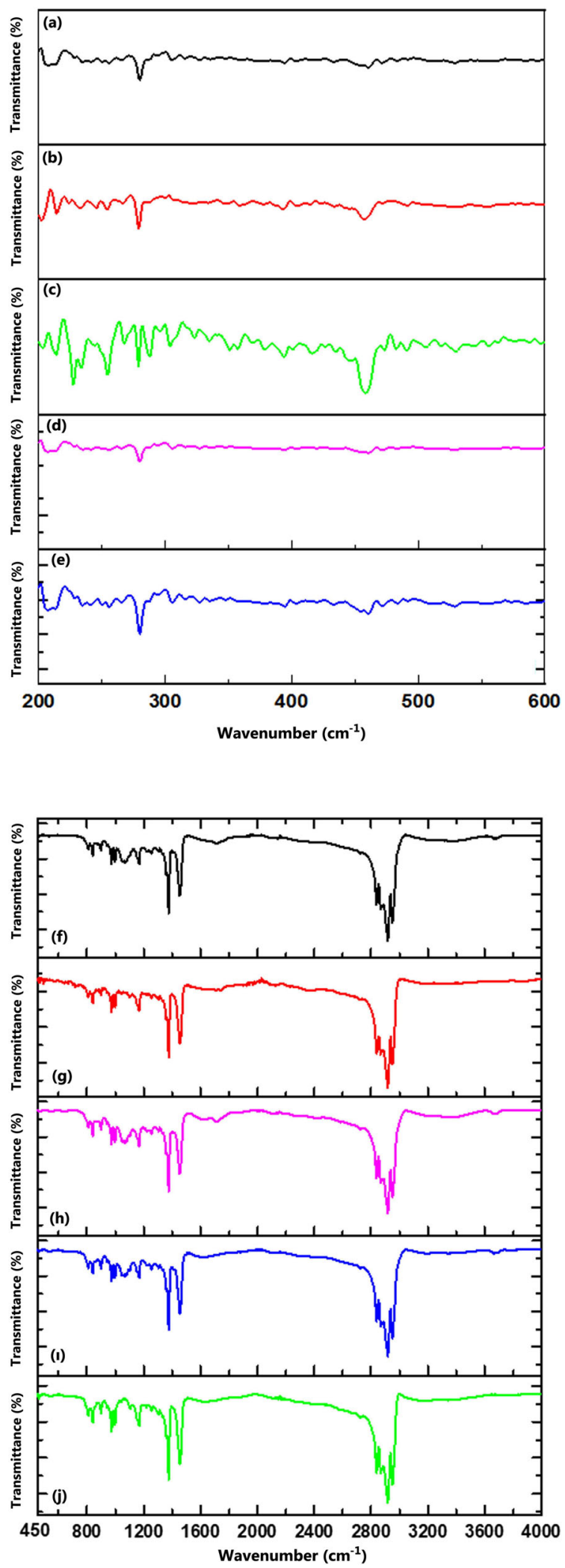
Fig. 1 Fourier transform infrared spectroscopy spectrums of the samples. a Fourier transform infrared spectroscopy analysis $\left(200-600 \mathrm{~cm}^{-1}\right)$ of the pure polypropylene. b Fourier transform infrared spectroscopy analysis $\left(200-600 \mathrm{~cm}^{-1}\right)$ of the $0.5 \%$ fumed silica-doped polypropylene. c Fourier transform infrared spectroscopy analysis $\left(200-600 \mathrm{~cm}^{-1}\right)$ of the $1 \%$ fumed silica-doped polypropylene. d Fourier transform infrared spectroscopy analysis $\left(200-600 \mathrm{~cm}^{-1}\right)$ of the $1.5 \%$ fumed silica-doped polypropylene. e Fourier transform infrared spectroscopy analysis $\left(200-600 \mathrm{~cm}^{-1}\right)$ of the $2 \%$ fumed silica-doped polypropylene. Fourier transform infrared spectroscopy analyses were performed in the wavelength range of $200-600 \mathrm{~cm}^{-1}$ to see both polypropylene and $\mathrm{Si}-\mathrm{O}$ vibrations. f Fourier transform infrared spectroscopy analysis $\left(450-4000 \mathrm{~cm}^{-1}\right)$ of the $2 \%$ fumed silica-doped polypropylene. $\mathrm{g}$ Fourier transform infrared spectroscopy analysis $\left(450-4000 \mathrm{~cm}^{-1}\right)$ of the $1.5 \%$ fumed silica-doped polypropylene. $\mathbf{h}$ Fourier transform infrared spectroscopy analysis $\left(450-4000 \mathrm{~cm}^{-1}\right)$ of the $1 \%$ fumed silica-doped polypropylene. i Fourier transform infrared spectroscopy analysis $\left(450-4000 \mathrm{~cm}^{-1}\right)$ of the $0.5 \%$ fumed silica-doped polypropylene. j Fourier transform infrared spectroscopy analysis $\left(450-4000 \mathrm{~cm}^{-1}\right)$ of the pure polypropylene. Si-O at $1372-1453 \mathrm{~cm}^{-1}$ and Si-OH vibration peaks are seen at $969 \mathrm{~cm}^{-1}$.

\section{Scanning electron microscope (SEM) and energy dispersive $X$ - ray (EDX) analysis}

SEM and EDX analysis results are given in Figs. 2 and 3. In Fig. 2a, the TEM image of pure PP without doping shows a flat ground except for a small agglomeration due to the extruder machine's principle pull. Figure $2 \mathrm{~b}$ shows large $\mathrm{SiO}_{2}$ particles around $200 \mathrm{~nm}$ identified when $0.5 \% \mathrm{Si}$ is added. The particle size in Fig. $2 \mathrm{c}$ is $200 \mathrm{~nm}$ and below, and in Fig. 2d, there is an agglomerated coarse particle. In Fig. 2e, the particles are agglomerated more in certain regions as the doped amount increases, which indicates why no more than 2\% can be added to PP. Because the agglomerated particles disconnect from the polymer and cause holes and ruptures on the surface during extraction. Even though FS is in nano size, it is added from the extruder machine's reservoir. FS begins to agglomerate due to the environment's humidity at this temperature, which is $\sim 200^{\circ} \mathrm{C}$. When it enters into the structure of the molten PP, it can agglomerate in certain areas. However, when the added amount is small and added to the extruder machine simultaneously, there is very little agglomeration. However, in the case of excessive agglomeration, ruptures may be seen in the structure of PP. In the experiments, critical ruptures were observed in the polymer when $3 \%$ or more of FS were added to PP.

According to the EDX analysis given in Fig. 3, when $0.5 \%$ of FS is added, the very low amount of silicon on the polymer surface increases as the doping increases. The amount of silicon in the structure increased from 0.07 to $0.76 \%$ with doping. However, when 1.5 and $2 \%$ FS is doped into PP, the strip-form polymer structure deteriorated due to the reasons above. In other studies in the literature, the FS doped to the polymers was also agglomerated after exceeding a certain amount ${ }^{38}$.

\section{Surface tension measurements}

According to the Zisman method, a solid's surface tension is calculated from the slope of the line drawn by plotting the contact angle $(\cos \theta)$ between the solid and the liquid dropped on that solid versus these liquids' surface tension $(\sigma)$. The slope of that line gives the surface tension of that solid. Moreover, when looking at liquids that are standardly dropped onto the solid surface, they are generally polar molecules. In other words, by adding a hydrophilic material, the angle of contact will decrease. The decrease in the contact angle causes the slope of the intended line to be low. Therefore, as the doping of a hydrophilic material increases, the surface tension is expected to increase, which can be seen very clearly from Zisman's mathematical formula.
Zisman found that $\cos \theta$ is a function $\sigma_{l}$

$\cos \theta=a-b \sigma_{l}=1-\beta\left(\sigma_{l}-\sigma_{\mathrm{cr}}\right)$

$\sigma_{\mathrm{cr}}$ represents a solid's critical surface tension, which is a common characteristic property for all solids. $\sigma_{l}>\sigma_{\mathrm{cr}}$ in liquids that wet the surface. This method is commonly used to measure the polymers' surface tension. The contact angle between the liquid and the solid $(\cos \theta)$ is plotted versus the surface tension $(\sigma)$ of these liquids, and the line's slope is obtained. The line here is $y=a x+b$. The polymer's surface tension is calculated from the slope " $a$ "39,40. Figure 4 shows the curves drawn by the Zisman method and the water's contact angle with the produced fog harvesting materials. The water's contact angle with the fog harvesting materials is measured as $103^{\circ}$ for pure PP, $97^{\circ}$ for $\% 0.5$ Si-doped PP, $92^{\circ}$ for $\% 1$ Si-doped PP, $100^{\circ}$ for \%1.5 Si-doped PP, and $102^{\circ}$ for $\% 2$ Si-doped PP. If the water droplet spreads by wetting a large area of the surface, the contact angle is less than $90^{\circ}$, and the surface is considered hydrophilic. In our study, the hydrophilic properties of the materials have a very fine line. The highest efficiency obtained from 1\% Si-doped PP also has the lowest contact angle of $92^{\circ}$, which is quite close to the hydrophilic and hydrophobic limit. In this study, the highest fog harvesting efficiency was achieved when water's contact angle with the material surface is below $100^{\circ}$.

The literature often reported that the water to be collected depends on the surface tension. In Fig. 4, the samples' surface tension, measured by using the Zisman method, is shown. Water, diiodomethane, ethylene glycol, and formamide with known surface tension values were used. After measuring these liquids' contact angles with the surface, these contact angles were plotted versus the surface tension. Our samples' surface tensions were calculated from the slope of the line obtained, and the results are presented in Fig. 5. While the surface tension of pure PP was $16.754 \mathrm{mN} / \mathrm{m}$, the surface tension decreased to 13.512 and $9.992 \mathrm{mN} / \mathrm{m}$ when 0.5 and $1 \%$ FS was doped, respectively. However, the 1.5 and $2 \%$ FS-doped polymer's surface tension increased again to 20.6 and $38.1 \mathrm{mN} / \mathrm{m}$.

Figure 6 shows the average amount of water stored on the materials' surface in an hour. Pure PP was used as a reference in this study. The materials with a surface area of $50 \mathrm{~cm}^{2}$ were weighted. The amount of water that can be collected per $1 \mathrm{~g}$ of material is given in Fig. 7. As the researchers have stated before, the materials' surface tension is effective in collecting water. The amount increased up to $0.267 \mathrm{~g} / \mathrm{g}$-material $/ \mathrm{cm}^{2}$ with $1 \% \mathrm{FS}$ doping, whereas this value decreased to the amount of the undoped PP for 2\% FS-doped PP.

In Fig. 8, the relationship between surface tension and the amount of collected water is given. The only data that disrupts this curve is undoped PP; thus, it has been removed from this chart. FS is one of the best humectants. It is hydrophilic. FS increases its weight in just a few minutes by absorbing up to $0.5 \%$ moisture, and then it can desorb very easily. Therefore, an increase of Si\% in the structure up to a certain level indicates an increase in FS. The more FS, the more water will be absorbed into the structure. As shown in Fig. 8, there is also a relation such as surface tension $=5.0648$ (deposition water) 0.452 , although it is not a very compatible graphic.

\section{DISCUSSION}

Regarding the studies involving undoped PP, around $0.05 \mathrm{~g}$ of water can be collected with an angle of $90^{\circ}$ between the sample and the fogger (in a $60-65 \%$ humidity) ${ }^{25}$. In their study, Raut et al. stated that cellulose fibers could store five times more water than pure PP. Among the studies about water collection in the literature, Kim et al. produced $\mathrm{ZnO}$ and $\mathrm{Ag}$ nanostructured materials; they reported collecting up to $0.3 \mathrm{~g} / \mathrm{cm}^{2}$ water with a machine that fogged water at a speed of $120 \mathrm{~mL} / \mathrm{h}$, at $\sim 11.50^{\circ}$ angle $(70 \% \text { humidity })^{41}$. Although Almasian et al. stated that they could collect $300 \mathrm{mg}$ of water in a $70^{\circ}$ humidity environment with fluorinated-PAN nanofibers, they did not 

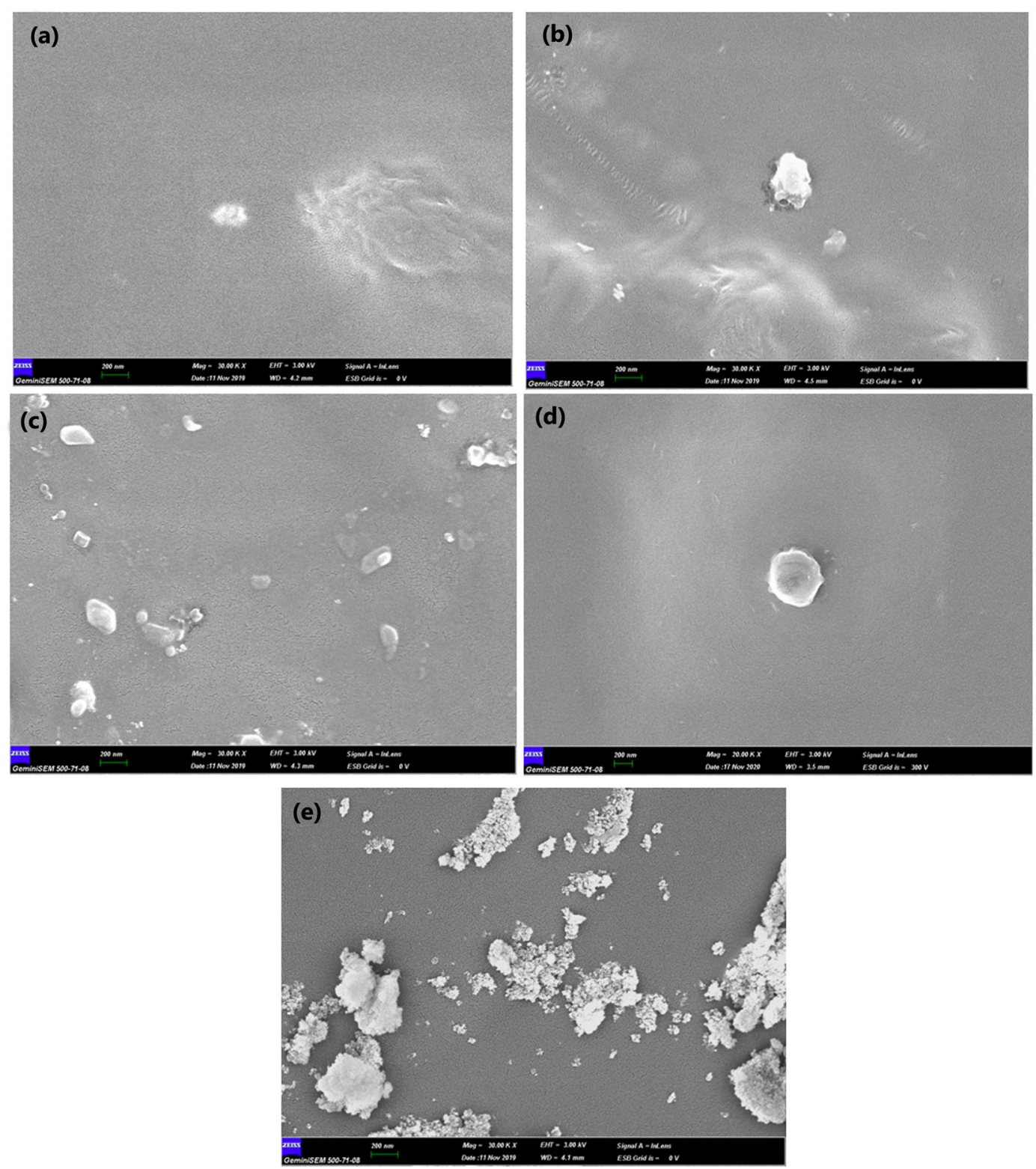

Fig. 2 Scanning electron microscope images of the samples. a Scanning electron microscope image of pure polypropylene without doping shows a flat ground except for a small agglomeration due to the extruder machine's principle pull. b large $\mathrm{SiO}_{2}$ particles around $200 \mathrm{~nm}$ are detected when $0.5 \%$ fumed silica is added. c Particle size $200 \mathrm{~nm}$ and below. d An agglomerated coarse particle. e Particles more agglomerated in certain regions as the doping increases, which indicates why no more than $2 \%$ can be added to polypropylene.

give information such as ultrasonic power fogger and the amount of water produced per hour ${ }^{42}$. Zhong et al. stated that they could collect $0.3 \mathrm{~g} / 600 \mathrm{~mm}^{2}$ water with the materials they produce from copper and titanium oxide; they used a powerful ultrasonic fogger of $252 \mathrm{~mL} / \mathrm{h}$ and $70 \mathrm{~cm} / \mathrm{s}$, at $70 \%$ humidity ${ }^{43}$.

On the other hand, Gürsoy et al. showed that $107 \mathrm{~g} / \mathrm{m}^{2}$ water was collected with a $30 \mathrm{~L} / \mathrm{h}$ fogger using natural fibers, and $58 \mathrm{~g} / \mathrm{m}^{2}$ of water can be collected with the polyethylene polymer they used as a reference. Twice as much water can be collected compared to a normal polymer ${ }^{44}$. White et al. tested different materials they prepared with polytetrafluoroethylene (PTFE), aluminum, titanium, and carbon nanotubes in a closed container with a fogger of $420 \mathrm{~mL} /$ h. They could collect $0.7 \mathrm{~g}$ of water with PTFE, and they increased this value to $0.8 \mathrm{~g}$ with the material they made from aluminum ${ }^{45}$.

As can be seen, it is not easy to compare the results of this study with the literature since each researcher created and used his/her parameters. The literature review showed that researchers not mentioned here have generally performed their experiments in the humidity chamber, in a high humidity environment, and using high-performance foggers. It would be much better to consider studies that use the same material as a reference. In some studies, the humidity of the environment was almost three times higher than our study, and the speed of the foggers was 6-100 times higher than ours. Therefore, it is more logical to look at studies such as that of Raut et al., White et al., and Gürsoy et al. Among these, only Raut et al. compared the material they have produced with a base material such as PP and stated that they could collect up to five times more water. It has been proven that up to 19-20 times more water can be collected with 1\% FS-doped PP than pure PP, with a fogger of $20 \mathrm{~mL} / \mathrm{h}$, without humidity chamber and at $20 \%$ humidity at room conditions. No material in the known literature can collect so much water. This material also has its disadvantages. Besides, when $3 \%$ or more of FS was added to PP, deterioration (ruptures) was observed in the sample structure. Also, when $2 \%$ or 

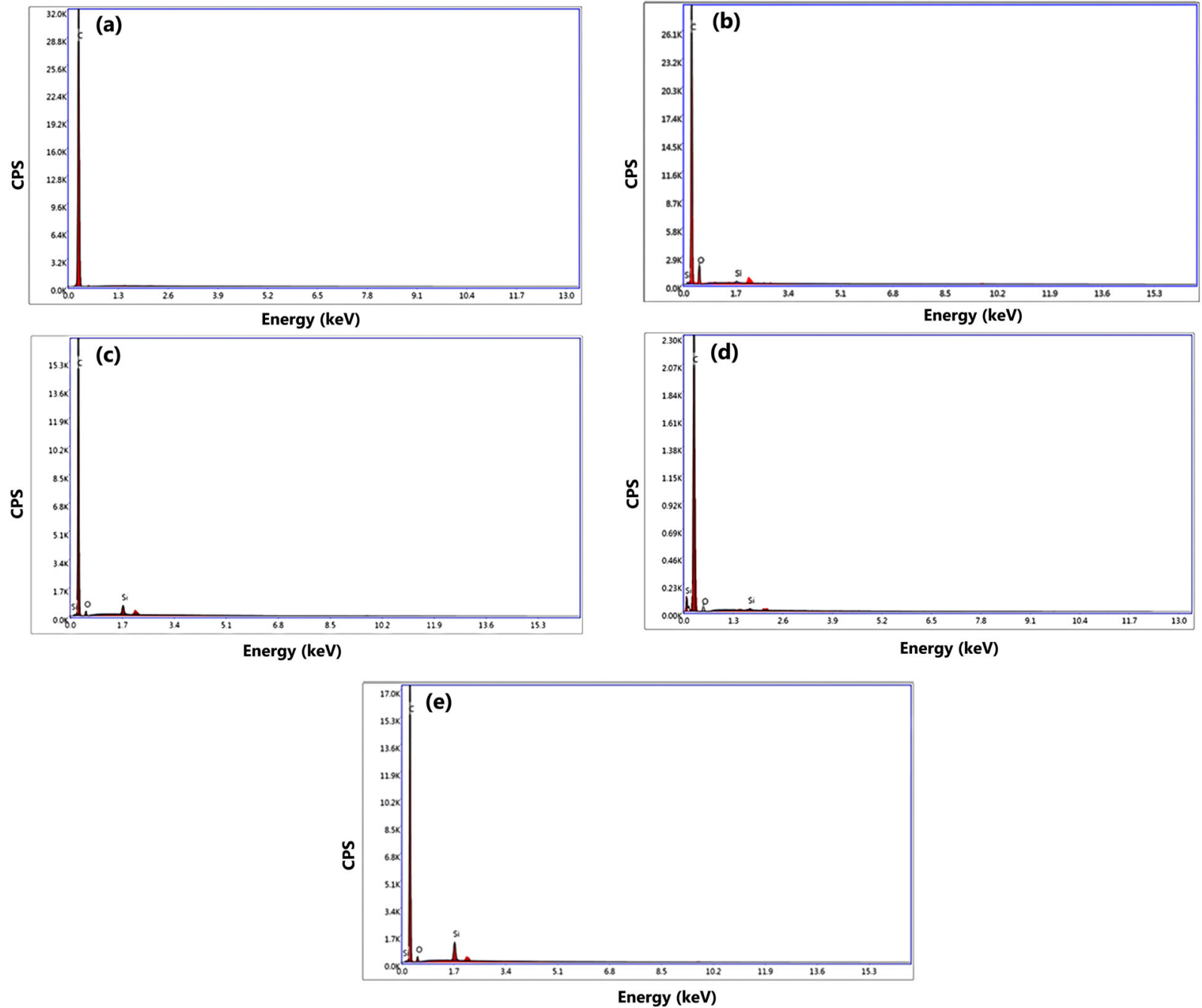

Fig. 3 Energy dispersive X-ray spectrometer analysis of the samples. a Undoped, pure polypropylene. b $0.5 \%$ fumed silica-doped polypropylene. c $1 \%$ fumed silica-doped polypropylene. d $1.5 \%$ fumed silica-doped polypropylene. e $2 \%$ fumed silica-doped polypropylene. The amount of silicon in the structure increased from 0.07 to $0.76 \%$ as the doping increase.

more of FS was added to PP, there was a decrease in the fog harvest. This is because FS is also a good moisturizer and tries to keep water in its structure by swelling. Also, with the increase of agglomeration due to excessive doping, the nonhomogeneous distribution of FS in PP reduces the efficiency.

PP was used as a reference in this study. Hydrophilic FS was doped to a hydrophobic material (PP) by $0.5-1-2 \%$. One percent of FS-doped PP was found to collect almost 19-20 times more water than pure PP. However, one of the main findings of the study is the surface tension. In this study, the material with the lowest surface tension collected the maximum amount of water. However, it was not easy to compare the obtained results with the literature. Since the parameters that researchers specified vary in each study, the comparison was made according to the reference material. In terms of cost, we produced almost 50-100 times cheaper materials than those known in the literature, which were claimed to be good in collecting water.

\section{METHODS}

\section{Preparation of fog harvesting materials}

In this study, fog harvesting materials (PP and FS-doped PP (Si-PP)) were produced via extruder machine. FS (Si) was purchased from Sigma Aldrich. $\mathrm{SiO}_{2}$ molecular weight was $60.08 \mathrm{~g} / \mathrm{mol}$. Physical properties were: surface area: $200 \mathrm{~m}^{2} / \mathrm{g}\left( \pm 25 \mathrm{~m}^{2} / \mathrm{g}\right)$, bulk density: $2.3 \mathrm{lb} / \mathrm{cu} . \mathrm{ft}$, and average particle size: $0.2-0.3 \mu \mathrm{m}$. Different proportions of FS solid powder $(0.5-1-2 \% \mathrm{Si})$ were added to PP via extruder machine (Gülnar Machine). Pure PP was used as a reference in this study. In the extruder machine $(16 \mathrm{~mm}$ double screw, L/D: 40 ), the inlet temperature was $50^{\circ} \mathrm{C}$ while doping the polymer, and the feed temperatures were set to $180,190,200,200$, and $190^{\circ} \mathrm{C}$. Strips of $113.5 \mathrm{~cm}$ in length, $6.1 \mathrm{~cm}$ width, and micron-size thickness were produced from $6.75 \mathrm{~g}$ of polyethylene. Concentrated glycerin, iodomethane, deionized water, and ethylene glycol were used for contact angle measurements. The test liquids' surface tension was defined using the pendant drop method (KSV CAM200, KSV Instruments, Finland). All measurements were performed at $21{ }^{\circ} \mathrm{C}$.

The polymers produced from the extruder in the form of film strips were cut rectangularly in an area of $50 \mathrm{~cm}^{2}$. Holes were opened on the samples with a pin tip to facilitate the airflow (Fig. 9).

These samples were then hung one by one at a distance of $10 \mathrm{~cm}$ opposite a small fogger machine (Lemon Humidifier, working voltage: DC5V, water capacity: $180 \mathrm{~mL}$ spray amount: $20 \mathrm{~mL} / \mathrm{h}$ ) (Fig. 7). The same procedures were applied for all samples. The experiment was carried out under normal room conditions, at $20 \%$ humidity, and in an open room closed to the airflow (Fig. 10). Figure 10a shows the water droplets collected on the sample in $1 \mathrm{~min}$. In Fig. 10b, the diameter of the holes drilled on the materials was taken through different measurements. Accordingly, the average hole's diameter on the samples was $450.6 \mu \mathrm{m}$. The smallest hole diameter was $295 \mu \mathrm{m}$, and the largest one was $550 \mu \mathrm{m}$. No holes with a smaller or larger diameter than these values were found. 


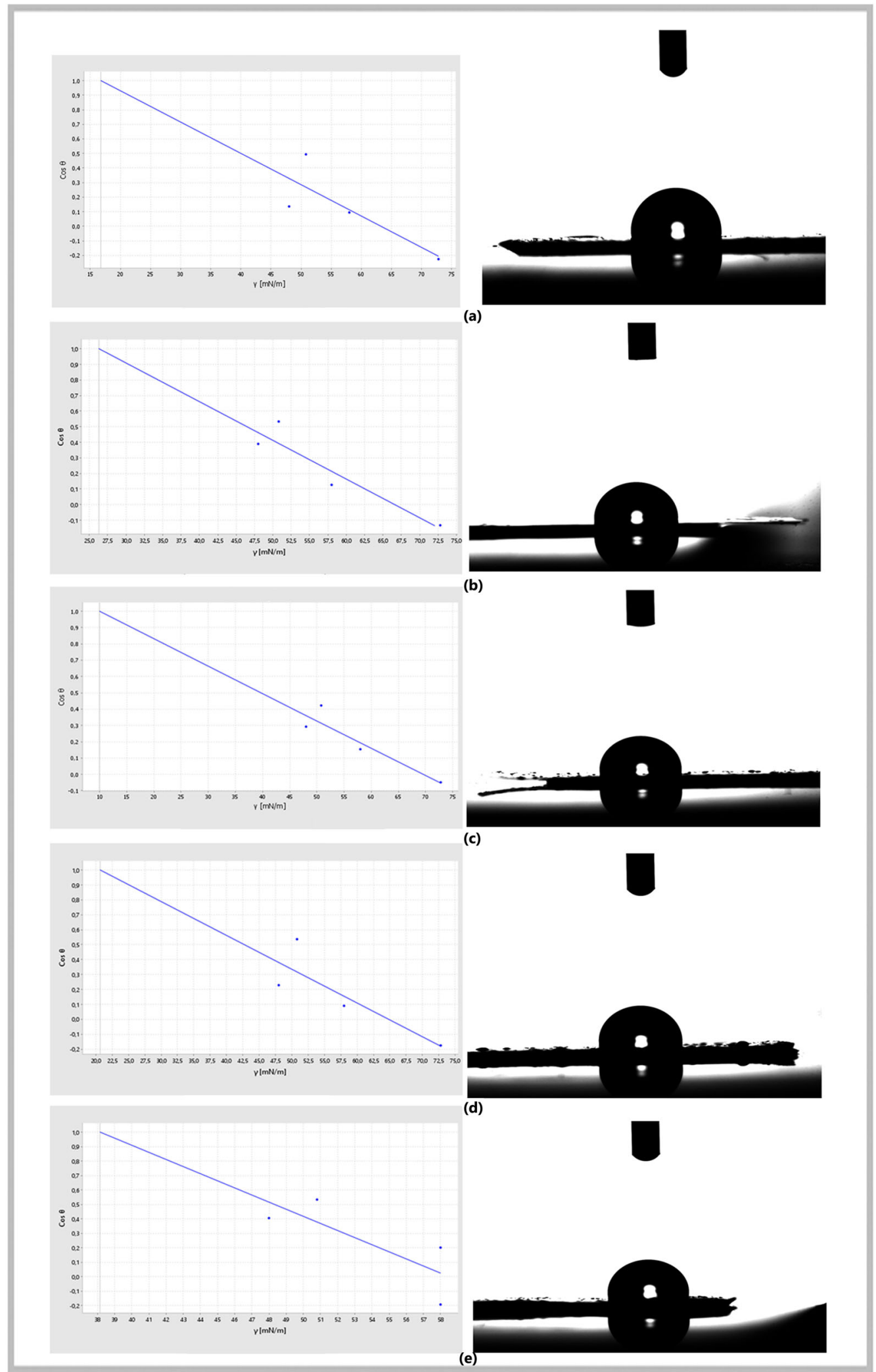

Fig. 4 Zisman plot and water drop on the surface of the samples. a Pure polypropylene Zisman plot and water drop on the surface. $\mathbf{b} 0.5 \%$ fumed silica-doped polypropylene Zisman plot, and water drop on the surface. c $1 \%$ fumed silica-doped polypropylene Zisman plot and water drop on the surface. d $1.5 \%$ fumed silica-doped polypropylene Zisman plot and water drop on the surface. e $2 \%$ fumed silica-doped polypropylene Zisman plot and water drop on the surface. The water's contact angle with the fog harvesting materials is measured as $103^{\circ}$ for pure polypropylene, $97^{\circ}$ for $0.5 \%$ fumed silica-doped PP, $92^{\circ}$ for $1 \%$ fumed silica-doped PP, $100^{\circ}$ for $1.5 \%$ fumed silica-doped $\mathrm{PP}$, and $102^{\circ}$ for $2 \%$ fumed silica-doped PP. $\cos \theta$ is drop angel on the surface and $\gamma$ is surface tension of the test liquids. 


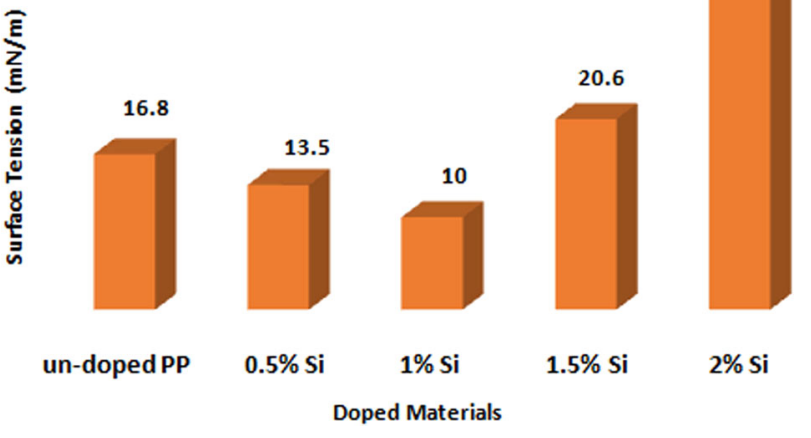

Fig. 5 Surface tension of the fog harvesting materials. While the surface tension of pure polypropylene was $16.754 \mathrm{mN} / \mathrm{m}$, the surface tension decreased to 13.512 and $9.992 \mathrm{mN} / \mathrm{m}$ when 0.5 and $1 \%$ fumed silica was doped, respectively.

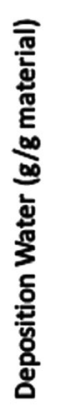

un-doped PP

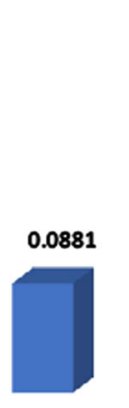

$0.5 \% \mathrm{Si}$
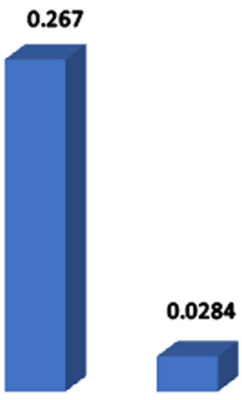

0.0193

$1 \% \mathrm{Si}$

$1.5 \% \mathrm{Si}$

$2 \% \mathrm{Si}$
Deposition Materials

Fig. 6 The amount of collected water according to fog harvesting materials. The amount of water increased up to $0.267 \mathrm{~g} / \mathrm{g}$-material/ $\mathrm{cm}^{2}$ with $1 \%$ fumed silica doping, whereas this value decreased to the amount of the undoped polypropylene with $2 \%$ fumed silica doping.

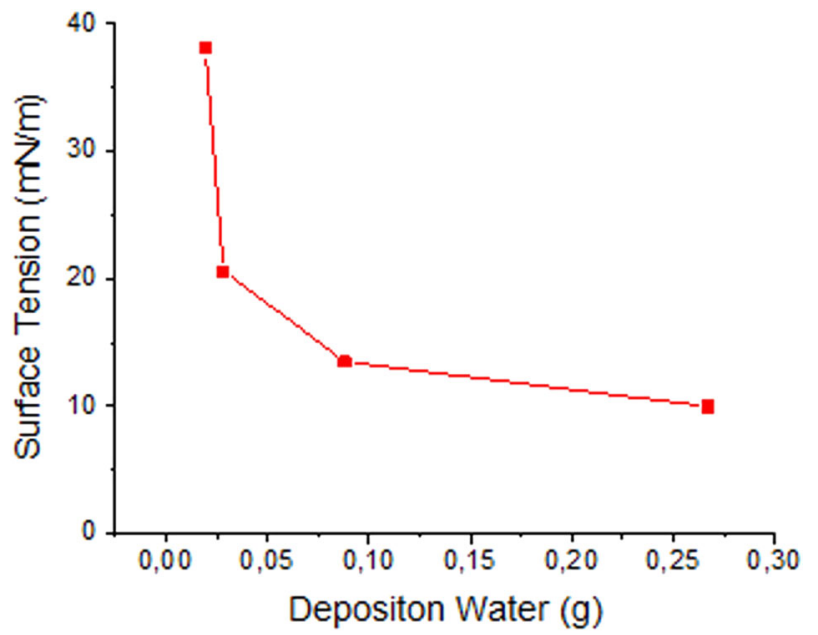

Fig. 7 Experimental design. The samples were then hung one by one at a distance of $10 \mathrm{~cm}$ opposite a small fogger machine.

\section{Analysis}

The materials' surface properties were examined using an EVO40-LEO computer-controlled digital SEM. Quantitative elemental analysis was performed with an EDX spectrometer attached to SEM (EDAX Octane).

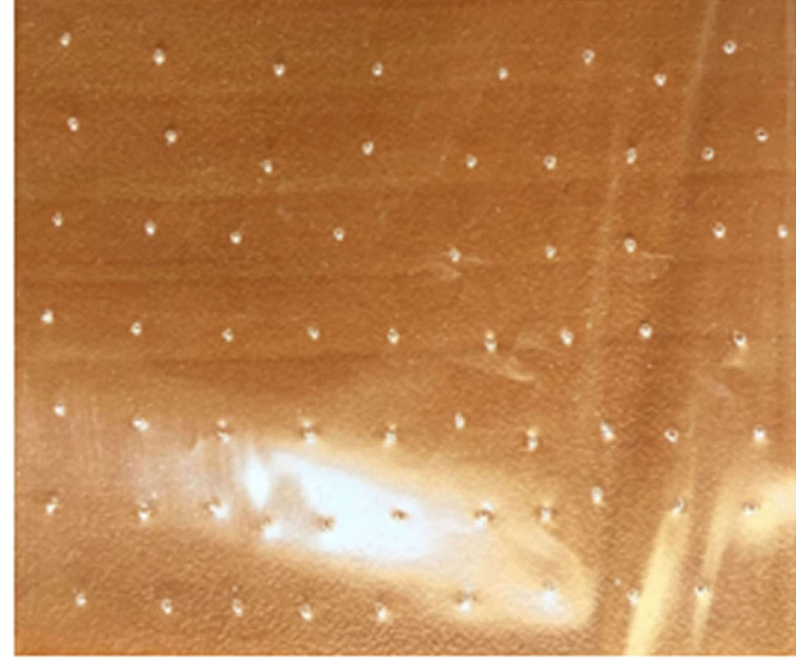

Fig. 8 Relationship between surface tension and the amount of collected water. An increase of silicon $\%$ in the structure up to a certain level indicates an increase in fumed silica. There is also a relation such as surface tension $=5.0648$ (deposition water) -0.452 , although it is not a very compatible graphic.
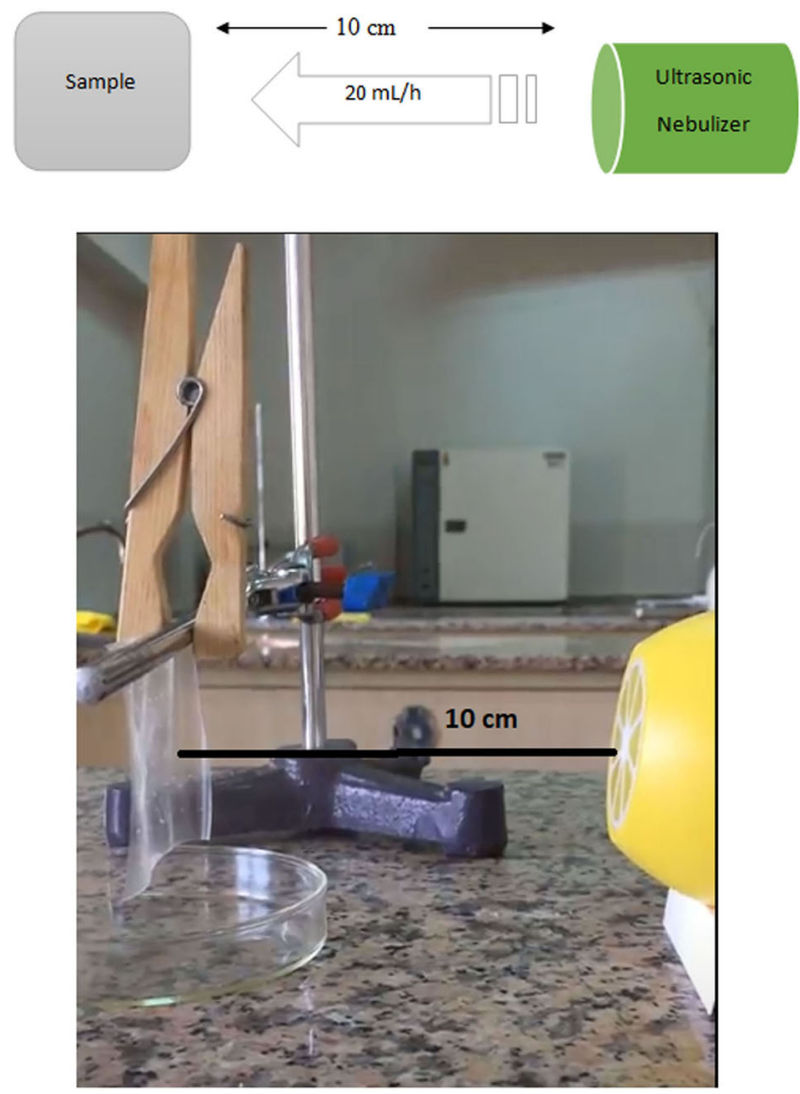

Fig. 9 Polypropylene sample. The samples produced from the extruder in the form of film strips were cut rectangularly in an area of $50 \mathrm{~cm}^{2}$. Holes were opened on the samples with a pin tip to facilitate the airflow.

The surface tensions were measured using KSV CAM200, KSV Instruments, at room temperature, under room condition, and controlled airflow. An analytical balance weighed the water collected on the sample surface. FTIR device (Bruker Alpha, having a resolution of $4 \mathrm{~cm}^{-1}$; equipped with a DTGS detector, performing ten scans for each spectrum) was used to record vibration peaks. 


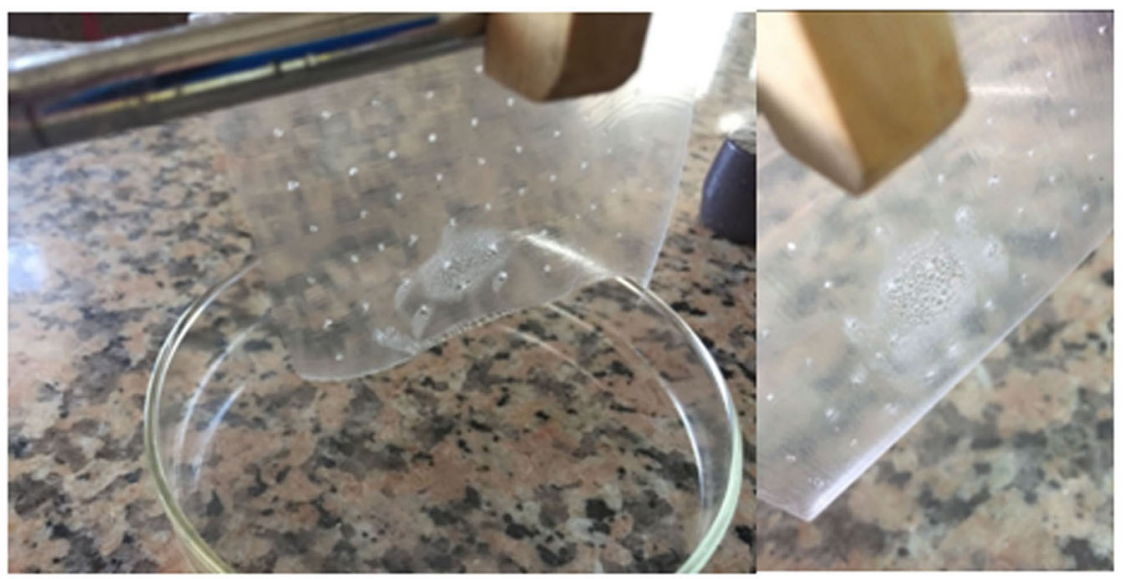

(a)
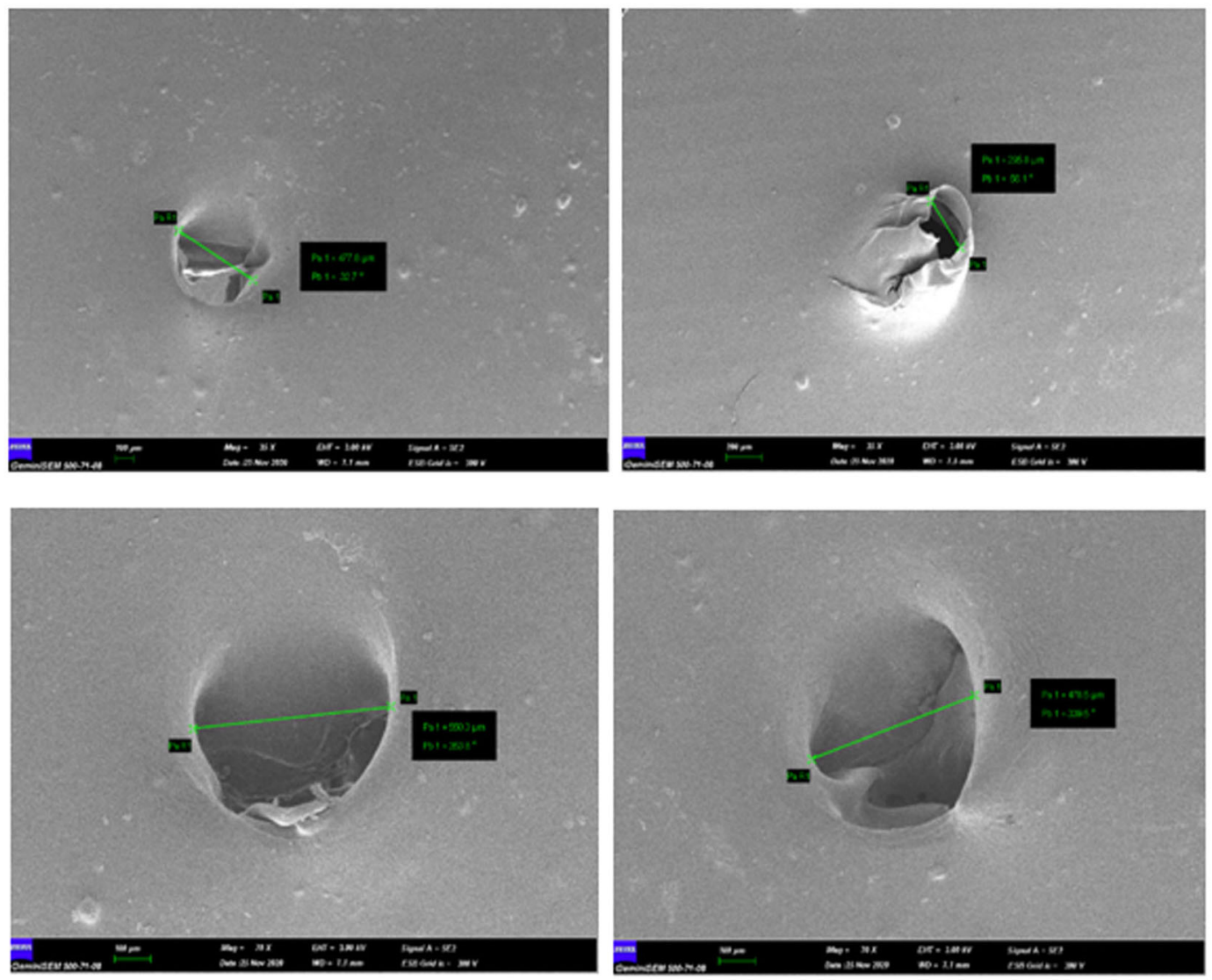

(b)

Fig. 10 Water collected in $1 \mathrm{~min}$, and the diameter of the holes on the sample surfaces, scanning electron microscope images. a The water droplets collected on the sample in $1 \mathrm{~min}$. $\mathbf{b}$ The diameter of the holes drilled on the materials was taken through different measurements. The experiment was carried out under normal room conditions, at $20 \%$ humidity, and in an open room closed to the airflow.

\section{DATA AVAILABILITY}

The datasets generated during and/or analyzed during the current study are available from the corresponding author on reasonable request.

Received: 10 September 2020; Accepted: 16 March 2021; Published online: 08 April 2021

\section{REFERENCES}

1. Sun, M., Watson, G. S., Zheng, Y., Watson, J. A. \& Liang, A. Wetting properties on nanostructured surfaces of cicada wings. J. Exp. Biol. 212, 3148-3155 (2009).

2. Malik, F. et al. Dew harvesting efficiency of four species of cacti. Bioinspiration Biomim. 10, 036005 (2015).

3. Zhang, H. et al. Surface modification of electrospun polyacrylonitrile nanofiber towards developing an affinity membrane for romelain adsorption. Desalination 256, 141-147 (2010). 
4. Azad, M. A. et al. Fog collection on polyethylene terephthalate (PET) fibers: influence of cross-section and surface structure. Langmuir 33, 5555-5564 (2017).

5. Weinman, C. J. et al. $A B C$ triblock surface active block copolymer with grafted ethoxylated fluoroalkyl amphiphilic side chains for marine antifouling/foulingrelease applications. Langmuir 25, 12266-12274 (2009).

6. Sundaram, H. S. et al. Fluorine-free mixed amphiphilic polymers based on PDMS and PEG side chains for fouling release applications. Biofouling 27, 589 (2011).

7. Ndayambaje, G. et al. Adsorption of nickel(II) on polyacrylonitrile nanofiber modified with 2-(2'-pyridyl)imidazole. Chem. Eng. J. 284, 1106-1116 (2016).

8. Akhtar, F. H., Kumar, M. \& Peinemann, K. V. Pebax ${ }^{\boxplus 1657 / g r a p h e n e ~ o x i d e ~ c o m p o s i t e ~}$ membranes for improved watervapor separation. J. Membr. Sci. 525, 187-194 (2017).

9. Akhtar, F. H. et al. Highways for water molecules: interplay between nanostructure and watervapor transport in block copolymer membranes. J. Membr. Sci. 572, 641-649642 (2019).

10. Kostal, E., Stroj, S., Kasemann, S., Matylitsky, V. \& Domke, M. Fabrication of biomimetic fog-collecting superhydrophilic-superhydrophobic surface micropatterns using femtosecond lasers. Langmuir 34, 2933-2941 (2018).

11. Zhu, H. \& Guo, Z. Hybrid engineered materials with high water-collecting efficiency inspired by Namib Desert beetles. Chem. Commun. 52, 6809-6812 (2016)

12. Zhang, L., Wu, J., Hedhili, M. N., Yang, X. \& Wang, P. Inkjet printing for direct micropatterning of a superhydrophobic surface: toward biomimetic fog harvesting surfaces. J. Mater. Chem. A 3, 2844-2852 (2015).

13. Park, K. C. et al. Condensation on slippery asymmetric bumps. Nature 531, 78-82 (2016).

14. Medici, M. G., Mongruel, A., Royon, L. \& Beysens, D. Edge effects on water droplet condensation. Phys. Rev. E 90, 062403 (2014).

15. Viovy, J. L., Beysens, D. \& Knobler, C. M. Scaling description for the growth of condensation patterns on surfaces. Phys. Rev. A 37, 4965-4970 (1988).

16. Gandhidasan, P. \& Abualhamayel, H. I. Fog collection as asource of freshwatersupply in the Kingdom of Saudi Arabia. Water Environ. J. 21, 19-25 (2007).

17. Zhang, L., Zhong, Y., Cha, D. \& Wang, P. A self-cleaning underwater superoleophobic mesh for oil-water separation. Sci. Rep. 3, 2326 (2013).

18. Pan, Q. \& Wang, M. Miniature boats with striking loading capacity fabricated from superhydrophobic copper meshes. ACS Appl. Mater. Interfaces 1, 420-423 (2009).

19. Cheng, Z., Du, M., Fu, K., Zhang, N. \& Sun, K. pH-controllable water permeation through a nanostructured copper mesh film. ACS Appl. Mater. Interfaces 4, 5826-5832 (2012).

20. Wang, C. et al. Facile approach in fabricating superhydrophobic and superoleophilic surface for water and oil mixture separation. ACS Appl. Mater. Interfaces 1, 2613-2617 (2009).

21. Liu, X. C., Chakraborty, A. \& Luo, C. Fabrication of micropatterns on the sidewalls of a thermal shape memory polystyrene block. J. Micromech. Microeng. 20, 095025 (2010).

22. Lee, A., Moon, M. W., Lim, H., Kim, W. D. \& Kim, H. Y. Water harvest via dewing. Langmuir 28, 10183-10191 (2012)

23. Choo, S., Choi, H. J. \& Lee, H. Water-collecting behavior of nanostructured surfaces with special wettability. Appl. Surf. Sci. 324, 563-568 (2015).

24. Korkmaz, S. \& Kariper, İ. A. Fog harvesting against water shortage. Environ. Chem Lett. 18, 361-375 (2020).

25. Raut, H. K., Ranganath, A. S., Baji, A. \& Wood, K. L. Bio-inspired hierarchical topography for texture driven fog harvesting. Appl. Surf. Sci. 465, 362-368 (2019).

26. Moazzam, P., Tavassoli, H., Razmjou, A., Warkiani, M. E. \& Asadnia, M. Mist harvesting using bioinspired polydopamine coating and microfabrication technology. Desalination 429, 111-118 (2018)

27. Chin, J. Y., Teoh, G. H., Ahmad, A. L. \& Low, S. C., Superhydrophobic surface coating on electrospun polypropylene membrane to treat high saline water in membrane distillation. Water Sci. Technol. 82, 2948-2961 (2020). https://doi.org/ 10.2166/wst.2020.528

28. Damak, M. \& Varanasi, K. K. Electrostatically driven fog collection using space charge injection. Sci. Adv. 4, eaao5323 (2018).

29. Shi, W., Anderson, M. J., Tulkoff, J. B., Kennedy, B. S. \& Boreyko, J. B. Fog harvesting with harps. ACS Appl. Mater. Interfaces 10, 11979-11986 (2018).

30. Domen, J. K., Stringfellow, W. T., Camarillo, M. K. \& Gulati, S. Fog water as an alternative and sustainable water resource. Clean Technol. Environ. Policy 16 235-249 (2014)

31. Olivier, J. Fog-water harvesting along the West Coast of South Africa: a feasibility study. Water SA 28, 349-360 (2002).

32. Batisha, A. F. Feasibility and sustainability of fog harvesting. Sustain. Water Qual. Ecol. 6, 1-10 (2015)

33. Mavukkandy, M. O., Bilad, M. R., Kujawa, J., Al-Gharabli, S. \& Arafat, H. A. On the effect of fumed silica particles on the structure, properties and application of PVDF membranes. Sep. Purif. Technol. 187, 365-373 (2017).
34. Luna-López, J. A., Carrillo-López, J., Aceves-Mijares, M., Morales-Sánchez, A. \& Falcony, C. FTIR and photoluminescence of annealed silicon rich oxide films. Superficies y Vacío 22, 11-14 (2009).

35. Andreasen, E. Infrared and Raman spectroscopy of polypropylene. in Polypropylene: an A-Z Reference (ed Karger-Kocsis, J.) (Kluwer Publ., 1999).

36. Liang, Y. et al. Synthesis and characterization of core-shell structured $\mathrm{SiO}_{2} @ \mathrm{YVO}_{4}$ : $\mathrm{Yb}^{3}+, \mathrm{Er}^{3+}$ microspheres. Appl. Surf. Sci. 258, 3689-3694 (2012).

37. Krylova, V. \& Dukštienè, N. Synthesis and characterization of $\mathrm{Ag}_{2} \mathrm{~S}$ layers formed on polypropylene. J. Chem. 2013, 987879. https://doi.org/10.1155/2013/987879.

38. Kim, J. H. et al. Dye-sensitized nanocrystalline solar cells based on composite polymer electrolytes containing fumed silica nanoparticles. Chem. Commun. 10 1662-1663 (2004).

39. Kariper, İ. A. What is the effect of critical surface tension of $\mathrm{PbSO}_{3}$ thin film? Metall. Mater. Trans. A 45, 4398-4404 (2014).

40. Kariper, İ. A. Critıcal surface tension, critical surface energy and parachor of $\mathrm{MnSO}_{3}$ thin film. Surf. Rev. Lett. 23, 1650009 (2016).

41. Kim, N. K., Kang, D. H., Eom, H. \& Kang, H. W. Biomimetic fog harvesting surface by photo-induced micro-patterning of zinc-oxide silver hierarchical nanostructures. Appl. Surf. Sci. 470, 161-167 (2019).

42. Almasian, A., Chizari Fard, G., Mirjalili, M., \& Parvinzadeh Gashti, M. FluorinatedPAN nanofibers: preparation, optimization, characterization and fog harvesting property. J. Ind. Eng. Chem. 62, 146-155 (2018).

43. Zhong, L., Zhu, H., Wu, Y. \& Guo, Z. Understanding how surface chemistry and topography enhance fog harvesting based on the superwetting surface with patterned hemispherical bulges. J. Colloid Interface Sci. 525, 234-242 (2018).

44. Gürsoy, M., Harris, M. T., Carletto, A., Yaprak, A. E., Karaman, M. \& Badyal, J. P. S. Bioinspired asymmetric-anisotropic (directional) fog harvesting based on the arid climate plant Eremopyrum orientale. Colloids Surf Physicochem Eng Aspects 529, 959-959 (2017).

45. White, B., Sarkar, A. \& Kietzig, A. M. Fog-harvesting inspired by the Stenocara beetle-an analysis of drop collection and removal from biomimetic samples with wetting contrast. Appl. Surf. Sci. 284, 826-836 (2013).

\section{ACKNOWLEDGEMENTS}

The author thanks Erciyes University.

\section{AUTHOR CONTRIBUTIONS}

The author is inventive and performed experiments, tests, and writing.

\section{COMPETING INTERESTS}

The author declares no competing interests.

\section{ADDITIONAL INFORMATION}

Correspondence and requests for materials should be addressed to I.A.K.

Reprints and permission information is available at http://www.nature.com/ reprints

Publisher's note Springer Nature remains neutral with regard to jurisdictional claims in published maps and institutional affiliations.

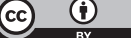

Open Access This article is licensed under a Creative Commons Attribution 4.0 International License, which permits use, sharing, adaptation, distribution and reproduction in any medium or format, as long as you give appropriate credit to the original author(s) and the source, provide a link to the Creative Commons license, and indicate if changes were made. The images or other third party material in this article are included in the article's Creative Commons license, unless indicated otherwise in a credit line to the material. If material is not included in the article's Creative Commons license and your intended use is not permitted by statutory regulation or exceeds the permitted use, you will need to obtain permission directly from the copyright holder. To view a copy of this license, visit http://creativecommons. org/licenses/by/4.0/.

(c) The Author(s) 2021 